"arreglo nítido" de los datos, sino también en el sentido estricto lingüístico de la palabra 'sistematizar'. Es decir, hay que describir los datos de manera que esta misma descripción teórica y cartográfica nos facilite la formulación de reglas variables al llegar al próximo paso en el análisis de estos datos así cartografiados.

Universidad de California, Los Angeles.

JERRY MCMENAMin

\title{
UN FALSO NAHUATLISMO
}

En la preparación del vocabulario de origen indigena usual en el español hablado hoy en Méxicol participaron activamente 18 investigadores, y su contenido fue revisado por un número también elevado de estudiosos. Bajo la mirada vigilante de todos nosotros se deslizó, disfrazado de nahuatlismo, un término de muy distinto origen, que a todos engañó por su apariencia azteca; me refiero a la forma ate, muy usual en México² con el significado de 'pasta dulce' o 'dulce en pasta' hecho de diversas clases de fruta $^{3}$. Nuestro espejismo puede explicarse -aunque no justificarse- por diferentes razones. En primer lugar, por el hecho de estar ausente en todos los diccionarios de la lengua española consultados, de lo cual cabía deducir que no se trataba de una voz hispánica. En segundo lugar, por su propia forma, de aspecto "obviamente" nahoa: el morfema ate figura en multitud de vocablos mexicanos, de muy diverso significado, como mecate, zacate, petate, cuate, itacate, metate, paliacate, tanate, chilpayate, tepetate, tompiate, etc.; y figura, particularmente, en términos relativos a frutos o productos alimenticios -como aguacate, tomate y jitomate, cacahuate, etc.- y, aún más concretamente, como elemento formativo de voces que designan cierto tipo de bebidas o, precisamente, cierta clase de pastas dulces hechas de fruta: lo primero, en casos como chocolate, pinolate, pozolate, chilate, etc.; lo segundo, en formaciones como guayabate, duraznate, mangate, membrillate, fresate, calabazate, peronate, etc., todas las cuales equivalen a "(pasta) dulce de guayaba, de durazno", etc., o lo que es lo mismo "ate de guayaba, de durazno", etc. De manera que ese vocablo ate se identifica, casi necesariamente, con el morfema "nahoa" integrante de tantos y tantos indigenismos mexicanos ${ }^{4}$. Tal fue el espejismo que sufrimos todos los que participamos en la elaboración del librito mencionado.

1 Juan M. Lope Blanch, Léxico indigena en el español de México, México, 1969.

2 Por su vitalidad y por el grado de conocimiento por parte de los hablantes mexicanos, el vocablo ate quedó incluido en el segundo grupo, correspondiente a las "voces de conocimiento casi general" (cf. pp. 35 y 36 del Léxico indigena).

3 Quienes tuvieron la gentileza de comentar el librito, una vez publicado, tampoco descubrieron al intruso.

4 En su Diccionario de seudoaztequismos (Cuernavaca, 1906) Cecilio A. RoBELo nada dice en torno al término ale, como si no fuera éste un tremendo y engañoso "seudoaztequismo". Recoge, sí, como tales a guayabate y a mangate, pero lo hace en cuanto derivados de guayaba y de mango, términos que algunos tenían erróneamente por nahuatlismos. 
Espejismo igual -aunque independiente de él ${ }^{5}-$ al que había sufrido mucho antes Marcos Becerra, al analizar esas designaciones de los dulces de fruta mencionados: "Cabe sospechar la presencia de un elemento formativo de origen nahoa en todos estos nombres [guayabate, durazna$t e$, etc.], pues la terminación ate puede venir de atl, que significa 'agua', i referirse al método de fabricación de estas pastas, que reclaman una considerable adición de agua para darles el punto de jalea que les es característico"6. No cabe duda de que ese componente -ate, procedente del náhuatl, es el que forma parte de las designaciones de las bebidas mencionadas: chocolate, pozolate, etc. 7 . Pero en identificarlo con el ate de las pastas dulces es en lo que radica el error en que incurrimos.

Error que la consulta del Tesoro de la lengua española (Madrid, 1611) de Sebastián de Covarrubias, me hizo advertir. Al preparar algunos trabajos sobre la labor lexicográfica de Covarrubias, en que me he ocupado recientemente, descubrí que los términos calabazate, codonate y piñonate figuran ya en su diccionario ${ }^{8}$. Imposible suponer que se tratara de mexicanismos - de formaciones hispanoamericanas- que hubiera traspasado el Atlántico y arraigado ya de tal modo en el habla peninsular como para que Covarrubias los recogiese como voces naturalmente hispánicas. Esto me puso sobre la pista verdadera y esto me obliga a rectificar la suposición de que la palabra ate tenga origen nahoa. Y en Covarrubias se apunta, además, la pista particular y precisa que conduce a la verdad. En efecto, en la entrada referente al membrillo, advierte el lexicógrafo toledano: "En Valencia llaman al membrillo o conserva codoñate". Origen, pues, oriental, no propiamente castellano, en el caso de estas formaciones léxicas. Lo demás ha sido muy fácil.

Por un lado, cabe consignar que las formaciones con ate designadoras de 'pasta dulce de fruta' y también de 'guisado hecho con (el nombre de la base)' abundan en el español peninsular; una rápida consulta a los diccionarios más conocidos me ha permitido reunir los siguientes: calabazate, codoñate, membrillate, piñonate (todos 'dulce de'), y almendrate (guisado) e higate (potaje). Además, estas denominaciones se documentan desde antiguo: piñonate ya en 1525, y codoñate desde mucho antes: figura en el Arcipreste de Hita $y$, en aragonés,

5 En nuestra seguridad de que esa voz ate se identificaba con el morfema ate de los nombres compuestos mexicanos, y en nuestra certeza de que ese morfema no podía ser sino de origen nahoa, no nos preocupó mucho el no poder identificarlo con alguno de los elementos constitutivos del náhuatl. Así, no nos esforzamos por documentarlo bibliográficamente, y no tuvimos entonces en cuenta la opinión de Becerra que ahora transcribo.

- Marcos E. Becerra, Rectificaciones $i$ adiciones al Diccionario de la Real Academia Española, México, 1954; p. 15.

7 Cf. Cecilio A. Robelo, Diccionario de aztequismos, $3^{\mathrm{a}}$ ed., México. Por ejemplo, s. v. "CHILATE (CHIL-ATL: chilli, chile; atl, agua: "aguachil o agua de axi», dice Molina). Bebida muy usada en las costas, compuesta de chile, cacao y agua".

8 De la primera dice: "Calabaçate, la conserva que se haze con la calabaça, que es fresca y saludable". De piñonate, "pasta de piñones y açucar". Juan Corominas, $D C E C, s . v$. pino) da como fecha de primera documentación de piñonate el año 1680; Covarrubias permite adelantarla setenta años. Para codoñate, cf. infra. 
desde $1373^{9}$. En la lengua renacentista abundaban también -y aún más que en el castellano moderno- los compuestos con -ate: sólo en el Libro de los guisados de Ruperto de Nola (Toledo, 1525) figuran avellanate, almendrate, calabacinate, higate, salviate, ordiate, bruscate, membrillate, romerate, avenate y persicate ${ }^{10}$. Son, pues, formaciones hispánicas que se transplantaron al Nuevo Mundo, donde arraigaron con fuerza. La peculiaridad mexicana actual consiste simplemente en el mayor vigor, la más acusada vitalidad de que gozan estas formas, frente a lo sucedido en el castellano peninsular, donde han caído en desuso. Y el verdadero mexicanismo - pero no nahuatlismo- radica en la constitución, como vocablo autónomo -fenómeno en verdad sorprendente e inusitado-, de ate ${ }^{11}$ a partir del morfema -ate integrante de las voces castellanas. Proceso ya apuntado por F. J. Santamaría con toda precisión, aunque sin alusión alguna al origen etimológico del morfema ate ${ }^{\mathbf{1 2}}$.

Por otra parte, el origen catalán de la terminación -ate, apuntado por Covarrubias, queda también fuera de toda duda: el cat, -at $(<$ lat. -ATU) se castellaniza en -ate, conforme lo sostiene Corominas (s.v. codoñate $)^{13}$, de cuya obra creo que ha pasado esa información al Diccionario de la Academia, donde se explican codoñate y piñonate como derivados, respectivamente, del cat. codonyat y pinyonat ${ }^{14}$.

Una vez más, la realidad prueba que es preciso ser muy cautos antes de imaginar explicaciones sustratísticas para hechos que pueden explicarse dentro del sistema interno de una lengua. Que las apariencias engañan...

Universidad Nacional Autónoma de México.

Juan M. Lope Blanch

9 Cf. Corominas, DCEC s.vv. codoñate y piñonate.

10 Aunque no piñonate, sino piñonada, como designación de un dulce hecho con piñones. En el Arte de cocina de Francisco Martínez Montiño se habla del calabazate. Tomo todos estos datos de Mariano de Cárcer y Dismier, Apuntes para la transculturación indoespañola, México, UNAM, 1953, pp. 51-52.

$11 \mathrm{La}$ industria de los ates es particularmente importante en la ciudad de Morelia (cf. Becerra, Rectificaciones, p. 15). La forma codoñate, desconocida hoy en México, fue también transplantada a la Nueva España durante la época virreinal: ha sido documentada en el libro de los Viajes de Tomas Gage a la Nueva España, de 1625 (cf. CÁrcer y Disdier, Apuntes, p. 55).

12 "Ate. Nombre genérico con que se designa una clase de dulces en pasta, hechos especialmente de frutas; por aféresis, suprimiendo el nombre de éstas: guayab-ATE, durazn-ATE, membrill-ATE, etc... En Filipinas se llama así el fruto de la anona, y dice Retana que es vocablo importado de Nueva España" (Diccionario de mejicanismos, Méjico, 1959, s.v.).

13 Quien ha estudiado también el problema relativo a la prioridad cronoló. gica de las terminaciones catalanas -at y -ac, y el referente a su procedencia: lat. -atum o gr. Larov (en el Homenaje a Rubio i Lluch, III, 311). En relación con -at como derivado del lat -ATU, téngase en cuenta la formación castellana paralela almendrado 'pasta hecha con almendras, harina y miel o azúcar' (DRAE). Pero es problema ajeno al que nos ocupa.

I4 En las ediciones del $D R A E$ anteriores a 1954 -fecha de publicación del Diccionario de Corominas- no se dice nada en torno a esa relación catalano-castellana de las voces indicadas. Tal relación se hace constar por primera vez en la $18^{\text {a }}$ edición del $D R A E$, aparecida en 1956. 